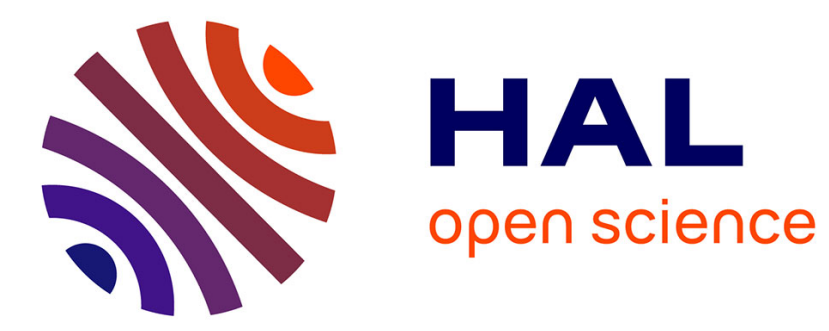

\title{
Karl Marx et les Roms des Principautés roumaines Leonardo Piasere
}

\section{To cite this version:}

Leonardo Piasere. Karl Marx et les Roms des Principautés roumaines . Etudes Tsiganes, 2016, 56-57, pp.235-260. 10.3917/tsig.056.0235 . hal-01448098

\section{HAL Id: hal-01448098 \\ https://hal.science/hal-01448098}

Submitted on 27 Jan 2017

HAL is a multi-disciplinary open access archive for the deposit and dissemination of scientific research documents, whether they are published or not. The documents may come from teaching and research institutions in France or abroad, or from public or private research centers.
L'archive ouverte pluridisciplinaire HAL, est destinée au dépôt et à la diffusion de documents scientifiques de niveau recherche, publiés ou non, émanant des établissements d'enseignement et de recherche français ou étrangers, des laboratoires publics ou privés. 


\section{KARL MARX ET LES ROMS DES PRINCIPAUTÉS ROUMAINES Leonardo Piasere}

FNASAT | «Etudes Tsiganes »

2016/1 n 56-57 | pages 235 à 260

ISSN 0014-2247

Article disponible en ligne à l'adresse :

http://www.cairn.info/revue-etudes-tsiganes-2016-1-page-235.htm

\section{Pour citer cet article :}

Leonardo Piasere, «Karl Marx et les Roms des Principautés roumaines 》, Etudes Tsiganes 2016/1 ( $\mathrm{n}^{\circ} 56-57$ ), p. 235-260.

DOI 10.3917/tsig.056.0235

Distribution électronique Cairn.info pour FNASAT.

(c) FNASAT. Tous droits réservés pour tous pays.

La reproduction ou représentation de cet article, notamment par photocopie, n'est autorisée que dans les limites des conditions générales d'utilisation du site ou, le cas échéant, des conditions générales de la licence souscrite par votre établissement. Toute autre reproduction ou représentation, en tout ou partie, sous quelque forme et de quelque manière que ce soit, est interdite sauf accord préalable et écrit de l'éditeur, en dehors des cas prévus par la législation en vigueur en France. Il est précisé que son stockage dans une base de données est également interdit. 


\section{Focus}

\section{Réflexion}

Karl Marx et les Roms des Principautés roumaines, Leonardo Piasere, p. 236

"La poursuite et l'extermination des Tsiganes en Ukraine pendant la seconde guerre mondiale ", Analyse du recueil des documents, matériaux et témoignages, Tatiana Sîrbu, p. 261

\section{Chroniques}

\section{Echo des assositions}

Nathalie Delon

Amnésies exhumées, Nathalie Delon, p. 265

\section{Livres}

Cécile Kovacshazy

De Punghina à Indre. Elles mijotent l'avenir, Association Romsi, p. 268

Catherine Poulain

Nous, notre Musique, on n'en parle pas, Héloïse Boullet, p.269

\section{Films}

Marie-Claude Vachez

Aferim, Radu Jude, p. 270

Cécile Kovacshazy

Spartacus \& Cassandra, loanis Nuguet, p. 271

\section{Exposition}

Marc Bordigoni

Grenoble, octobre 2015 : des incidents, une exposition et un livre, p. 272

\section{Théâtre}

Marie-Claude Vachez

La Tsigane de Lord Stanley par la Compagnie TAMÈRENTONG, p. 274 


\section{Karl Maxx et les Roms des Principautés roumaines ${ }^{1}$}

* Université de Vérone, Italie

Jusqu'à aujourd'hui, le passage le plus célèbre de Karl Marx qui renvoie de quelque manière aux Tsiganes se trouve dans Le 18 Brumaire de Lonis Bonaparte, écrit en 1852. L'auteur y faisait état du mépris qu'il avait à l'égard des partisans de Louis Bonaparte, qui se présentait comme « chef du sous-prolétariat » (Marx 1969 : 65). Notons au passage qu'en guise de titre, la traduction littérale de l'allemand Lumpenproletariat: le " prolétariat en haillons », - signifiant qui s'habille de haillons - aurait été beaucoup plus évocatrice, comme le souligne pertinemment Gianluca Solla (2013)². Dans son ouvrage, Marx écrivait :

A côté de "roués » ruinés, aux moyens d'existence douteux, et d'origine également douteuse, d'aventuriers et de déchets corrompus de la bourgeoisie, des forçats sortis du bagne, des galériens en rupture de ban, des filous, des charlatans, des lazzaroni, des pickpockets, des escamoteurs, des joueurs, des souteneurs, des tenanciers de maisons publiques, des porte-faix, des écrivassiers, des joueurs d'orgues, des chiffonniers, des rémouleurs, des rétameurs, des mendiants, bref, toute cette masse confuse, décomposée, flottante, que les Français appellent la «bobème » (1969: 65).

Ici, la bohème renvoie bien entendu à la bohème romantique d'Henry Murger, et non pas aux bobémiens en chair et en os du temps où ils en ont fourni la métaphore (cf. Lesnay 2008). Cette référence à la bohème n'est pas la seule dans les pages de Marx. Non seulement elle revient dans un autre passage du même ouvrage $^{3}$, mais elle apparaît déjà bien définie dans une description du monde des conspirateurs parisiens, rédigée en 1850. La vie déréglée des conspirateurs de profession, dont les quartiers généraux sont les tavernes, dit Marx,

Les situe dans le milieu social qu'à Paris on nomme la bohême. Ces bohémiens démocratiques d'origine prolétarienne - il existe aussi une bohême démocratique d'origine bourgeoise, ces démocrates flâneurs et piliers d'estaminet - sont donc soit des ouvriers qui, ayant abandonné leur travail se livrent à la débauche, soit des individus sortis du Lumpenproletariat qui adoptent toutes les manières dissolues de cette classe dans leur nouveau mode de vie. On concoit comment, dans ces circonstances, quelques repris de justice se trouvent impliqués dans presque tous les procès de conspiration. La vie entière de ces conspirateurs de profession est frappée du signe de la bohême [...] Somme toute, le marchand de vin leur tient lieu de véritable père des compagnons. C'est chez, lui que le conspirateur est le plus souvent à demeure [...] Déjà d'un tempérament très enjoué à l'image de tous les prolétaires parisiens, le conspirateur ne tarde pas à devenir un bambocheur accompli dans cette incessante ambiance de taverne. Le ténébreux conspirateur, qui affiche dans les séances secrètes une rigide vertu spartiate, soudain se dégèle et se transforme au sus de tous en pilier de cabaret, sachant, ô combien! apprécier le vin et les femmes [...] La principale caractéristique de la vie des conspirateurs est leur 
conflit avec la police, à laquelle ils ont en fait le même rapport que voleurs et prostituées (Marx, cit. in Cantimori Mezzomonti 1974 : 20-22)4.

Dans le développement du marxisme, la métaphore marxiste de la bohème est parfois retournée à sa source analogique sans perdre le mépris dont elle était saupoudrée. Dans les Quaderni dal carcere (Carnets de prison), l'un des fondateurs du Parti communiste italien et aujourd'hui l'un des héros des postcolonial studies, Antonio Gramsci, revient à plusieurs reprises sur le mouvement artistique de la bohème parisienne et, dans un passage fort peu connu (écrit entre 1930 et 1934), il le rapproche explicitement des Tsiganes. La vie tsigane est utilisée par le penseur et politicien sarde comme métaphore négative du «volontarisme des masses » qui rassemble des personnes hétérogènes, opposé au volontarisme positif des élites qui, lui, organise des groupes sociaux homogènes. Dans l'original en italien l'expression « attendamenti zingareschi e nomadi» (dont la traduction française « campements tsiganes et nomades » n'arrive pas à en donner le ton exotisant) apparaît dans le même court chapitre aux côtés de «Lumpenproletariat », " bohème » et «bohémiens», dans la trame d'un discours selon lequel les Tsiganes sont métaphoriquement opposés au parti politique en tant qu'avant-garde d'un bloc social homogène, sous la conduite des fameux «intellectuels organiques » :

La masse de salariés ruraux et du Lumpenproletariat qui, en Italie, porte le nom pittoresque de classe des "morts de faim » [...] Le parti d'action, mazinien et garibaldien [...] a été le prototype de tous les partis italiens successifs de « masse », qui en réalité n'en étaient pas (dans ce sens où ils n'établirent pas de groupes sociaux homogènes) mais qui furent plutôt des campements tsiganes et nomades de la politique [...] La position de Gottlieb [Amedeo Bordiga] fut précisément la même que celle du parti d'action, tsigane et nomade : l'intérêt pour le syndicat était très superficiel et d'origine polémique, non systématique, non organique ni conséquent, ce n'était pas un intérêt pour la recherche d'homogénéité sociale, mais un intérêt paternaliste et formaliste [...] On lutte contre ces dégénérescences de faux héroïsmes et de pseudo-aristocraties [...pour surmonter] leur domination tsigane. La bohème parisienne du Romantisme a été elle aussi aux origines intellectuelles de nombreux modes de pensée actuels, qui semblent railler également ces bohémiens (Gramsci 1971: 247-48).

Le rapprochement entre Tsiganes et Lumpenproletariat a émigré dans les sciences sociales internationales du $\mathrm{XX}^{\mathrm{e}}$ siècle, sous les appellations de «marginalité sociale », « déviance sociale », etc., et il reste le fondement d'un certain nombre de sociologies et de politologies contemporaines, ce qui confirme la force de cette métaphore marxienne apparemment innocente.

Mais je ne voudrais pas insister ici sur cet aspect de la prose marxienne et marxiste, qui doit être encore largement sondée et qui, par la métaphore à large spectre du binôme Lumpenproletariat-bobème, a investi les Tsiganes réels d'un cône d'ombre non édifiant. En ce qui nous concerne, ce cône d'ombre est important pour comprendre ce que Marx n'a pas écrit. En effet, au-delà de ces renvois 
métaphoriques, Marx n’a apparemment jamais évoqué les Tsiganes dans ses œuvres. Et pourtant... Pour apprécier ce que je m'apprête à dire, il faut laisser le communisme qui est encore attendu en Occident, pénétrer dans le socialisme réel des Balkans, et décrire brièvement ce qui a tout l'air d'être une intrigue internationale : en 1958, un historien polonais, Stanislas Schwann, découvre dans les archives Marx/Engels de l'Internationaal Institunt voor Sociale Geschiedenis (Institut international d'histoire sociale d'Amsterdam), quatre manuscrits inédits de Marx écrits entre 1855 et 1860 (Oțetea 1964 ; Petrescu 2008). S'agissant de documents qui parlaient des Principautés de l'époque, il informe ses confrères de l'Académie des sciences de Bucarest. Au début des années 1960, une équipe d'historiens roumains se met au travail pour déchiffrer et traduire les manuscrits d'une lecture ardue ( $c f$. Figure 1), et en 1964 cette même Académie publie le volume sous le titre Însemnări despre români: Manuscrise inedite (Notes sur les Roumains : Manuscrits inédits). Nous sommes à la période de la «Déclaration d'avril », alors que le Parti communiste roumain exprime les premières tentatives

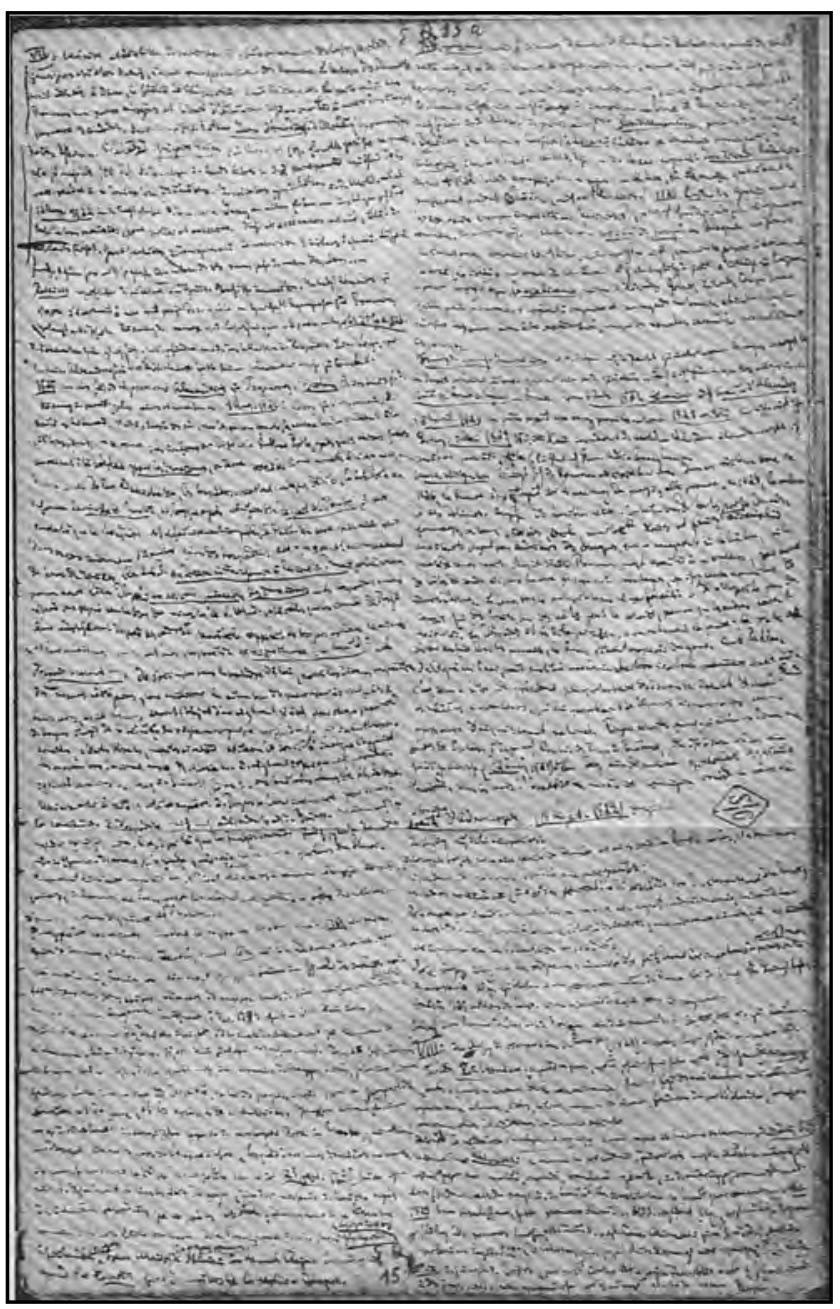

Figure 1 - Notes sur les Roumains : Insemnări despre români: Manuscrise inedite 
de faire sortir la Roumanie de l'orbite soviétique et de la russification de la culture nationale : en effet, dans sa verve anti-tsariste et anti-impériale, Marx décrivait les méfaits des différentes occupations militaires russes des principautés de Moldavie et de Valachie survenues pendant la première moitié du XIX ${ }^{\mathrm{e}}$ siècle. Il soutenait les revendications concernant l'unification des deux Principautés et reconnaissait la « roumanité » de la Bessarabie, la partie orientale de la Moldavie, occupée par les Russes dès 1812 et qui constitue depuis deux siècles un problème irrésolu.

Ce texte de Marx, amplement commenté et analysé aujourd'hui par les spécialistes du post-socialisme roumain ( $f f$. par ex. Petrescu 2008, Silvestru 2009), était en 1964 une bombe politique dans les relations roumanosoviétiques. De ce fait il disparut vite de la circulation, alors que paraissaient une édition en anglais, publiée en 1965 par rien de moins qu'une agence du gouvernement américain, et une édition italienne en 1971. Aujourd'hui, l'édition italienne est pratiquement introuvable et l'éditeur qui l'a publiée, la maison inconnue COO POE de Padoue, n'a peut-être publié que ce seul volume... Le texte italien, intitulé I russi in Romania (Les Russes en Roumanie), est accompagné de lithographies de Walter Piacesi dans lesquelles la luxure pornographique des boyards roumains renvoie analogiquement au désir de domination des Russes... L'éditeur et traducteur, Luciano Troisio, écrit dans l'introduction que cette édition s'inspire de l'édition roumaine, «dont la diffusion a été interdite en Roumanie, probablement sur ordre des Russes (après qu'une première édition de 25000 exemplaires ait été épuisée en un seul jour)» (1971: VIII), et remercie les spécialistes qui «ont été les premiers à déchiffrer les manuscrits» (p. 12), déclarant qu'il ne peut pas donner leur nom ${ }^{5}$. En somme, l'œuvre qui nous intéresse était, dans les intentions de Marx, ce que l'on nomme aujourd'hui un «paratexte», un manuscrit d'accompagnement de textes à publier, un paratexte qui, devenu texte imprimé, s'est transformé en centre d'intrigues internationales dans les années 1960 ; ce que Marx n’aurait jamais soupçonné dans les années 1850...

Et il ne l'aurait pas soupçonné, parce qu'il s'agit, précisément, des notes qu'il aurait prises pendant qu'il lisait un livere : l'Histoire politique et sociale des Principantés danubiennes, écrit par Élias Regnault et publié à Paris en 1855. Pour autant que je sache, Regnault n'avait jamais visité les Principautés, mais c'était un historien et un journaliste sérieux, et son ouvrage se fondait sur une bibliographie sélectionnée et mise à jour. À l'époque, il existait déjà divers ouvrages sur l'histoire des deux Principautés, et si Marx étudia celui de Regnault en particulier, c'est peut-être parce qu'il contient un chapitre de grand intérêt pour le Marx de ces années-là, qui approfondissait l'analyse de la plus-value et du surtravail. Le chap. XI du livre de Regnault est un tableau sociologique qui interrompt la description du flux des événements historico-politiques donnée par l'auteur avant 1848, pour exposer la situation socio-économique des Principautés, et notamment de la Valachie. Il s'agit de quatre-vingt-dix pages environ, qui 
décrivent l'organisation sociale fondée sur la division entre boyards (les nobles et notables locaux), paysans, clergé, classe moyenne de commerçants (quasi inexistante et composée de Juifs et de Grecs) et Tsiganes. La partie qui attire le plus l'attention de Marx est celle qui parle des paysans (ou mieux, celle qui parle des relations entre les paysans et les boyards), que Regnault avait compilée en suivant essentiellement l'étude de l'un des plus grands leaders de la révolution roumaine échouée de 1848, Nicolae Bălcescu : les Questions économiques des principautés danubiennes, publié à Paris en $1850^{6}$. Suivant Bălcescu, Regnault décrit en détail l'évolution du système des corvées auquel les paysans roumains étaient alors soumis, et les données de ces notes finiront dans le fameux chapitre huit du livre premier du Capital, dans lequel Marx démontrera les modalités de formation du surtravail. Ces problématiques, fondamentales dans la théorie marxienne puis marxiste, restent également au centre des réflexions contemporaines sur l'étude du rapport entre travail des immigrés et exploitation, dans le spectre esclavage/servitude/salariat (cf. Moulier Boutang 1998).

Cela dit, si les paysans et les boyards passent des notes de Marx à ses publications, il n'en est pas de même pour les Tsiganes, qui resteront confinés dans ce qui a été catalogué comme le «manuscrit B 85 » (le seul des quatre manuscrits - mais aussi le plus long - dans lequel ils figurent). Résumant Regnault, Marx les décrit ainsi dans ce manuscrit ${ }^{7}$ :

Triganes : esclavage; in beiden princip. Zus. 300.000 âmes, zablreicher in Moldau als Val. 140.000 in Transylv. Bucovina, Banat de Temeswar (Gypsies) (nennen sich Rômes.) 1848 le gouv. Provisoire proclama leur affranchissement.

1830 d. Boyars, déjà mécontents de perdre les scutelnici, lassen sich ihr Eigenthum auf d. gypsies consacrer durch Kisselef. 1834 le col. Campineano affranchissait tous ses esclaves. Dse meist ignorants et nus ne surent que faire d'une liberté qui les affamait. Stirbey zeichnete sich auf als Verkäufer v. Tziganes, erst en détail, dann d. Rest d. Banquier Oprano f. 120.000 fes. D. nationale Opposition wollte indemnité pour le rachat. Stirbey, d. effronté maquignon, will sich d. Verdienst dieses Gesetzvorschlages zueigen. Allgemeine Entrüstg. 1837 Alexandre Ghika ordonna l'affranchissement de tous les Tziganes appartenant à l'Etat. 4000 familles so befreit, auf $d$. Güter $d$. Boyars vertheilt, d. ihnen terres de labour gaben u. à l'égal d, paysans considérés sollten. Gyps-Abgaben an d. trésor (unter ihnen chaudronniers, serruriers, maréchaux ferrants etc.) Des 4000 familles bringen jzt d. Staat 90.000 fcs. Revenu.

31 Janv. 1844 Jean Stourdza présenta d. assemblée moldave un projet d'affranchissement des esclaves des monastères et du clergé (Marx 1964 : 66-67).

T.iganii : robie. In ambele principate tiganii formează o populație totală de 300000 de suflete, fiind mai numeroși în Moldova decît in Țara Românească; în Transilvania, Bucovina, Banatul Timisoarei, ei se ridică la 140 000. (În engleseste sînt numiţi Gypsies); (ei înşişsi se numesc romi). In 1848 guvernul provizoriu proclamă dezrobirea lor. In 1830, boierii, deja nemulțumiți de a-şi fi pierdut scutelnicii, obțin din partea lui Kiselev consacrarea dreptului lor de proprietate asupra tiganilor.

In 1834, colonelul Cimpineanu și-a eliberat toți robii. Cei mai mulți, ignoranți și goi, $n$-au 
stiut ce să facă cu o libertate care-i lăsa muritori de foame. Ştirbei s-a remarcat ca vînzător de tigani, mai întî cu bucata, apoi tot restul bancherului Opran pentru 120000 franci. Opositia naţională voia despăgubire pentru răscumpărare. Ştirbei, geambaşul neruşinat, a vrut să-şi atribuie meritul unui astfel de proiect de lege. Indignare generală.

In 1837, Al. Ghica a decretat eliberarea tuturor țiganilor aparținînd statului. 4000 de familii astfel eliberate au fost repartizate pe mosiile boierilor, cu obligatia pentru acestia a le da pămînt de ărătură şi de a-i trata deopotrivă cu ceialți țărani. Țiganii au fost impuşi la dări către vistierie. (Printre ei erau căldărari, lăcătuşi potcovari etc.). Aceste 4000 de familii aduc statului astăzi 90000 franci venit anual

La 31 ianuarie 1844, Ioan Sturdza a prezentat Obştești Adunări moldovene un proiect de dezrobire a robilor mănăstirilor şi clerului (Marx 1964 : 143).

(Les Tsiganes; esclavage. Dans les deux Principautés, les Tsiganes forment une population totale de 300000 âmes et ils sont plus nombreux en Moldavie qu'en Valachie ; en Transylvanie, en Bucovine, au Banat de Timisoara, ils sont 140000.

(En anglais, ils sont appelés Gypsies; eux-mêmes se font appeler : romi). En 1848, le gouvernement provisoire proclame leur affranchissement.

En 1830, les Boyards, qui étaient déjà mécontents d'avoir perdu les scutelnici, obtiennent de Kisseleff qu'il entérine leur droit de propriété sur les Tsiganes.

En 1834, le colonel Cîmpinean, libéra tous ses esclaves. La plupart d'entre eux, ignorants et nus, ne surent que faire d'une liberté qui les condamnait à mourir de faim.

Ştirbey se distingua comme vendeur de Tsiganes, au départ un à la fois, puis le reste, au banquier Oprano pour 120000 Francs. L'opposition nationale demandait une indemnité pour le rachat. Stirbey, vil courtier, voulut s'attribuer le mérite d'un tel projet de loi.

Indignation générale.

En 1837, Al[exandru] Gbica avait décrété la libération de tous les Tsiganes appartenant à l'État. Un nombre de 4000 familles ainsi libérées fut réparti sur le domaine des boyards, avec obligation pour ces derniers de leur donner de la terre à cultiver et de les traiter de la même manière que les paysans.

Les Tsiganes furent soumis à des droits envers la trésorerie. Parmi eux, il y avait des chaudronniers, des forgerons, des maréchaux-ferrants, etc. Aujourd'hui, ces 4000 familles rendent à l'État 90000 francs par an. Le 31 janvier 1844, Ion Sturdza présenta à l'Assemblée générale de Moldavie un projet d'affranchissement des esclaves des monastères et du clergé).

Malgré les imprécisions sur lesquelles je reviendrai dans un instant, Marx, comme on le voit, était parfaitement informé de l'état d'esclavage des Tsiganes dans les Principautés. Il savait entre autres que le projet de constitution de 1848, rédigé par les révolutionnaires nationalistes, prévoyait son abolition (1964 : 74, 152), il savait également qu'à certaines périodes historiques les caractéristiques de l'esclavage tsigane se confondaient avec celle des serfs de la glèbe. Esquissant la lutte historique entre les communautés de paysans libres et les boyards qui essayaient de les asservir, qui sera si bien décrite par Henri-Henri Stahl (1969) un siècle plus tard, il écrivait dans un autre passage du même manuscrit : 
Décadence vollendet dch. D. constitution de Serban d. d. propriétaire cultivateur en serf verwandlte. Sien un vkauft m. d. terres [...] D. propriétaire soll d. serf nicht getrennt von d. glèbe verkaufen; dss umggen. Bes. In d. Moldau, serfs confondus m.d. tziganes enclaves, vendus à la pièce » (Marx 1964 : 58).

Decăderea a fost săvîsşită prin constituția lui Şerban, care a transformat țăranul cultivator în şerb. Ei sînt acum vînduti impreună cu pămîntul [...] Proprietarul nu poate vinde pe şerb separat de pămînt. Aceasta [ultimă disposiție] este eludată. În Moldova, mai ales, serbii erau confundați cu țigani robi, venduți cu bucata (Marx 1964 : 134).

(La décadence fut totale avec la constitution de Şerban [prince de Valachie, milieu du XVII e s.], qui transforma le paysan cultivateur en serf [serb]. Maintenant, ils sont vendus avec les terres [...] Le propriétaire ne peut pas vendre le şerb séparément des territoires. Cette dernière prescription n'est pas souvent respectée. En Moldavie, en particulier, ces serfs [serbi] se confondaient avec les Tsiganes esclaves, lesquels étaient vendus par tête).

L'aspect du rapport entre la situation des Tsiganes esclaves et des paysans serfs n'entra jamais dans les réflexions générales de Marx concernant les rapports entre servitude et esclavage. Peut-être parce que leur coprésence dans les Principautés dérangeait sa reconstruction unilinéaire du passage de l'esclavage à la servitude de la glèbe? Peut-être parce que son préjugé anti-bobème le conduisait inconsciemment à bloquer son attention? Peut-être parce que les Tsiganes échappaient à la catégorie occidentale de vagabonds, à laquelle il pouvait associer les Gypsies anglais (et auxquels il les reliait lui-même), qui subirent les sanglantes répressions dont il parle dans le livre premier du Capital, lorsqu'il décrit la célèbre « accumulation primitive du capital » ? Peut-être pour tous ces aspects, et les spécialistes de Marx pourraient nous aider dans ce sens. Il n’en reste pas moins que l'entrée des Tsiganes dans les récits du fondateur du matérialisme dialectique n'apparaît que dans les parties inutilisées de ses paratextes, et nous pouvons dire qu'elle se configure donc comme une « paraentrée » : leur présence dans l'Europe en voie d'industrialisation ne fut pas considérée, ils n'étaient pas des individus sur qui on pouvait compter pour la révolution prolétaire, pas plus que l'incipit éclatant de Regnault dans son chapitre sur les Triganes ne suffit à attirer son attention :

La Moldo-Valaquie est le seul pays de l'Europe chrétienne où se rencontre encore l'esclavage (1855:329).

Si la publication des manuscrits pouvait déranger les gouvernants soviétiques des années 1960, qui découvraient même dans Marx le saint protecteur de l'indépendance roumaine et de la « Grande Roumanie », elle pouvait, d'un autre 
côté, déranger les gouvernants roumains de l'époque, eux-mêmes, lesquels n'ont jamais accepté une politique de reconnaissance des Roms (avec Ceauşescu, officiellement, les Tsiganes n'existaient pas), pas plus que leur socialisme nationaliste n'aurait pu supporter la construction d'un récit historique comprenant également l'existence de l'esclavage à côté de héros comme Alexandre le Bon ou Étienne le Grand. Je ne sais pas si c'est la publication roumaine des manuscrits de Marx de 1964 qui a suggéré les recherches précises sur l'esclavage en Moldavie publiées quelques années plus tard par Grigoraş $(1967,1968)$ et Cicanci (1967) - ils n'en parlent pas - mais quoi qu'il en soit, le sujet resta pratiquement tabou dans l'historiographie communiste qui suivit. Même les historiens roumains qui se sont occupés de la publication des manuscrits n'en parlent pas dans la présentation, pas plus que le sujet n'est abordé par le responsable de l'édition italienne, tous aveuglés par ce «nationalisme méthodologique » qui, dans ce cas, concernait la réunification de la Bessarabie à la Roumanie.

Marx note dans le manuscrit B 91 que les habitants de la Valachie et de la Moldavie étaient au nombre de quatre millions autour de 1848, et d'après les données indiquées plus haut, il aurait donc pu calculer que les Tsiganes esclaves représentaient $7,5 \%$ de la population. Aujourd'hui, nous savons que cette donnée fut pratiquement confirmée par les chiffres de 1859, qui se rapportaient aux esclaves émancipés avec indemnité de l'État, par suite des lois de 1855 et de 1856. Ces dernières donnaient une présence de Tsiganes de $7,13 \%$ en Valachie et de $7 \%$ en Moldavie (Achim 1998: 83) - le pourcentage $0,5 \%$ manquant pourrait se rapporter au nombre d'esclaves libérés, mais qui n'avaient fait l'objet d'aucune indemnité, en plus du nombre d'esclaves qui n'avaient pas, de fait, été libérés. Aujourd'hui, nous connaissons également mieux la situation générale : par exemple, en Valachie, sur les 2,5 millions d'habitants notés par Marx, 2 millions représentaient des paysans, dont $25 \%$ habitaient dans des villages libres et $75 \%$ dans des villages soumis aux corvées sur les terres des boyards. Ceux-ci, à leur tour, représentaient une minorité infime, s'agissant de 15500 personnes, mais leurs propriétés féodales représentaient pratiquement $80 \%$ de la superficie rurale du pays (Stan $1971: 14-15)$. Ce pouvait donc être une situation non secondaire pour l'étude qui intéressait Marx sur le passage du féodalisme au capitalisme. Bien qu'elle ait subi différentes variations au cours des siècles, et parfois des variations de nom (Mircea 1951), et compte tenu du fait que le concept d'« esclavage » est de type polythétique (Piasere 2012 : 83-84), la robie, comme était appelé en roumain l'esclavage tsigane à l'époque de Marx, pourrait être classée comme une forme intermédiaire entre celles que Moulier Boutang appelle « esclavage total » et « esclavage atténué » (2002: 646), mais plutôt déplacée vers ce deuxième pôle ${ }^{8}$. 


\begin{tabular}{|c|c|c|}
\hline Nature des droits & Esclavage total & Esclavage atténué \\
\hline 1. Aliénabilité & *Totale & Partielle \\
\hline 2. Droit personnel & Aucun en théorie & ${ }^{*}$ Indirect \\
\hline 3. Filiation & Aucune & *Indirecte (fils d'esclaves) \\
\hline 4. Sexualité & Castration masculine & *Interdiction de la castration \\
\hline $\begin{array}{l}\text { 5. Relations sexuelles avec } \\
\text { un conjoint libre }\end{array}$ & Interdits et punis & $\begin{array}{l}\text { *Tolérées ou affranchissantes } \\
\text { sous conditions }\end{array}$ \\
\hline 6.1 Nuptialité & Interdite & $\begin{array}{l}\text { *Tolérée, religieuse sans } \\
\text { valeur civile }\end{array}$ \\
\hline 6.2 Avec conjoint libre & *Interdite et punie & Toléré ou reconnue \\
\hline 7. Statut des enfants & *Celui de la mère & Celui du parent libre \\
\hline 8.0 Droits de propriété & Interdits & *Dérogatoires \\
\hline 8.1 Lopin & Non & *'Toléré, autorisé \\
\hline 8.2 Habitation & Non & Tolérée \\
\hline 8.3 Outils & Non & *Tolérés \\
\hline 8.4 Argent & Non & *Toléré ou admis (pécule) \\
\hline $\begin{array}{l}\text { 9. Accès à l'activité pour } \\
\text { soi, ou un tiers }\end{array}$ & Interdit & *Autorisé sous conditions \\
\hline 9.1 Vente de produits & Interdite & *Tolérée ou autorisée \\
\hline $\begin{array}{l}9.2 \text { Activité partielle libre } \\
\text { rémunérée }\end{array}$ & Interdite & $\begin{array}{l}* \text { Autorisée contre } \\
\text { rétrocession partielle des } \\
\text { gains }\end{array}$ \\
\hline 9.3 Terres et esclaves & *Interdits & Tolérés \\
\hline 10.0 Affranchissement & *Possible mais rare & Possible et fréquent \\
\hline 10.1 Manumission & *Exceptionnelle & À terme ou conditionnelle \\
\hline 10.2 Rachat & Interdit & $\begin{array}{l}* \text { Sous conditions ou sans } \\
\text { conditions }\end{array}$ \\
\hline
\end{tabular}

Tableau 1 - Les caractéristiques de l'esclavage tsigane dans les Principautés roumaines $\left.{ }^{*}\right)$ au début du XIX ${ }^{\mathrm{e}}$ siècle, d'après la grille de Moulier Boutang (1998 : 680)

Dans le Tableau 1, que je reprends à Moulier Boutang, j’ai ajouté un astérisque $\left(^{*}\right)$ marquant la situation que vivaient les robi des Principautés d'après les codes civils promulgués au début du XIX ${ }^{\mathrm{e}}$ siècle. La situation n'est pas toujours claire, mais du côté de l'esclavage total nous pouvons marquer l'aliénabilité (y compris la séparation des membres d'une famille), l'interdiction d'épouser des nonesclaves (ou des nobles), la condition des enfants (qui étaient esclaves ou libres suivant souvent la condition juridique de la mère, non du père), l'interdiction de posséder de la terre, les rares cas d'affranchissement qui, lorsqu'ils se produisent à l'époque de Marx, prennent la forme de ce que les anciens Romains appelaient manumissio censu, étant donné que les affranchis étaient automatiquement inscrits sur les liste des contribuables. Du côté de l'esclavage atténué, nous trouvons peut-être le cas plus important de l'existence de certains droits, tels que le droit à 
la vie (en théorie, le maître n'avait pas le droit de vie et de mort sur ses esclaves), le droit partiel à la propriété (de biens meubles, d'un jardin, non de grandes terres), et surtout la possibilité d'écouler les produits qu'ils fabriquaient en qualité d'artisans. De plus, signalons également l'interdiction faite aux maîtres de vendre un esclave à un étranger, signalée par quelques auteurs.

Je renvoie à d'autres études récentes pour d'autres caractéristiques sur l'état des esclaves tsiganes moldo-valaques (Codarcea 1998 et 2002 ; Achim 1998 et 2004 ; Piasere 2005 et 2014 ; Constantin 2007, 2009, 2012 ; Petcuț 2007 et 2009) ${ }^{9}$, car il s'agit ici de contextualiser la situation tsigane notée par Marx. Le contexte dans lequel il prend ses notes se situe à la veille de 1848, qui se caractérisa, dans les deux Principautés, comme un moment de la lutte entre les paysans et les seigneurs fonciers, cette fois à travers l'idéologie de la bourgeoisie naissante qui voulait importer dans la région un mode d'exploitation capitaliste des terres. La servitude de la glèbe avait été officiellement instaurée au XVIIe siècle, fixant le paysan à une propriété, mais au XVIII e siècle, avec l'entrée graduelle des Principautés dans le commerce international du blé, la servitude de la glèbe est officiellement abolie et remplacée par le système des corvées : les paysans ont de la terre qu'ils peuvent travailler pour eux-mêmes, mais ils doivent également travailler la terre du seigneur (à qui ils doivent aussi la dîme). En échange, les boyards obtiendront la formalisation de l'esclavage des Tsiganes et la création d'une nouvelle forme de serfs, les scutelnici, qui leur sont réservés pour les travaux domestiques et l'artisanat, et ils feront tout pour affaiblir la mobilité des paysans qui à présent, en théorie, sont détachés du fief. En effet, le système des corvées libère officiellement le paysan de la terre seigneuriale et le rapproche du salariat, mais, expliquait Marx dans Le Capital, alors que dans le travail salarié travail et surtravail se confondent, dans la corvée ils sont bien distincts ; ici, le surtravail

"A une forme indépendante, qui saute aux yeux [...] L'espace sépare le travail nécessaire que le paysan valaque, par exemple, exécute pour son propre entretien, de son travail extra pour le boyard. Le paysan exécute l'un sur son champ à lui et l'autre sur la terre seigneuriale. Les deux parties du temps de travail existent ainsi l'une à côté de l'autre d'une manière indépendante » (1974 : 286-287).

Et si pour le capitaliste, le désir d'augmenter le surtravail de l'ouvrier se traduit par des tentatives continues d'augmenter les heures de travail journalières, " chez le boyard, c'est tout simplement une chasse directe aux jours corvéables » (1974:287).

Marx s'intéresse beaucoup au système moldo-valaque parce que dans ces années-là, la lutte entre les paysans et les boyards semblait désormais définitivement gagnée par ces derniers. En 1831, il y avait eu l'entrée en vigueur du Règlement organique (Regolamentul Organic), une sorte de constitution rédigée par les boyards avec le contrôle direct des Russes, dans lequel le système des corvées 
s'avérait de manière disproportionnée tout à l'avantage des seigneurs fonciers, à un point tel qu'un boyard moldave, au moment de la promulgation, exultait en disant que les 12 journées annuelles officielles qu'un paysan devait au seigneur se montaient en fait à 365 jours! C'est essentiellement contre ce système, décrit en détail par Bălcescu, repris par Regnault, résumé par Marx dans les manuscrits puis dans Le Capital, qu'auront lieu les mouvements de 1848 dans les deux Principautés. Marx dira que dans le Règlement organique, « l'avidité de surtravail est légalisée à chaque paragraphe », et il le rebaptisera sous le nom de Code de la corvée, que les Russes firent passer comme innovant et qui conquit, dit Marx, « les applaudissements du crétinisme libéral de l'Europe entière » (1974 : 288-290).

\begin{tabular}{|c|c|c|c|c|c|c|c|c|c|c|c|}
\hline Județ & $\begin{array}{l}\text { Nb de } \\
\text { familles } \\
\text { tsiganes }\end{array}$ & $\begin{array}{l}\text { \%ude } \\
\text { tsiganes } \\
/ \text { total }\end{array}$ & $\begin{array}{l}\text { Tsigan } \\
\text { es de } \\
\text { l'État }\end{array}$ & $\begin{array}{l}9 / \text { de } \\
\text { rsigane } \\
\text { s/ total }\end{array}$ & $\begin{array}{l}\text { \% de } \\
\text { tsiganes/ } \\
\text { total du } \\
\text { Judet }\end{array}$ & $\begin{array}{l}\text { Tisigmes } \\
\text { des } \\
\text { monastères }\end{array}$ & $\begin{array}{l}9 / \mathrm{d} \text { de } \\
\text { tsiganes } \\
/ \text { pomal }\end{array}$ & $\begin{array}{l}\% \text { de } \\
\text { tsiganes/ } \\
\text { total } \% / \\
\text { du Judel }\end{array}$ & $\begin{array}{l}\text { Tsiganes } \\
\text { des } \\
\text { boyands }\end{array}$ & $\begin{array}{l}\text { \% sur le } \\
\text { total de } \\
\text { Tsiganes des } \\
\text { boyards }\end{array}$ & $\begin{array}{l}\% \text { de } \\
\text { tsiganes } \\
/ \text { total } \\
\text { Jude! }\end{array}$ \\
\hline $\begin{array}{l}\text { Slam } \\
\text { Rĩmnic }\end{array}$ & 2394 & 3,6 & 36 & 0,4 & 1,5 & 1.073 & 4,5 & 44,8 & 1.285 & 3,8 & 53,7 \\
\hline Bräila & 339 & 0.5 & 77 & 0,9 & 22,7 & 125 & 0.5 & 36.9 & 137 & 0,4 & 40,4 \\
\hline Buzâu & 4142 & 6,3 & 815 & 9,8 & 19,7 & 1.833 & 7,8 & 44,2 & 1.494 & 4,4 & 36,1 \\
\hline Sãcuieni & 4503 & 6,9 & 1179 & 14,2 & 26,2 & 2040 & 8,6 & 45,3 & 1284 & 3,8 & 28,5 \\
\hline Prahova & 3334 & 5,1 & 70 & 0,8 & 2,1 & 1312 & 5,6 & 39.3 & 1952 & 5,8 & 58,5 \\
\hline Ialomita & 2415 & 3,7 & 199 & 2,4 & 8,2 & 1290 & 5,5 & 53,4 & 926 & 2,7 & 38,3 \\
\hline Ilfov & 8002 & 12,2 & 739 & 8,9 & 9,2 & 1936 & 8,2 & 24,2 & 5327 & 15,8 & 66,6 \\
\hline Bucarest & 4609 & 7,0 & 184 & 2,2 & 4,0 & 246 & 1,0 & 5,4 & 4179 & 12,4 & 90,7 \\
\hline Dåmbovita & 4054 & 6.2 & 525 & 6,3 & 12,9 & 853 & 3,6 & 21,0 & 2676 & 7,9 & 66,0 \\
\hline Vlasca & 4317 & 6,6 & 757 & 9,1 & 17,5 & 1072 & 4,5 & 24,8 & 2488 & 7,4 & 57,6 \\
\hline Teleorman & 2217 & 3,4 & 472 & 5,7 & 21,3 & 586 & 2.5 & 26,4 & 1159 & 3,4 & 52,3 \\
\hline Muscel & 3319 & 5,1 & 846 & 10,2 & 25,5 & 1095 & 4,6 & 33,0 & 1378 & 4,1 & 45.5 \\
\hline Arges & 3566 & 5,4 & 757 & 9,1 & 21,2 & 1524 & 6,5 & 42.7 & 1285 & 3,8 & 35.9 \\
\hline Olt & 2244 & 3,4 & 261 & 3,1 & 11,6 & 738 & 3,1 & 32,9 & 1245 & 3,7 & 55,5 \\
\hline Romanati & 3619 & 5,5 & 58 & 0,7 & 1,6 & 1754 & 7,4 & 48,4 & 1807 & 5,3 & 49,9 \\
\hline Valcea & 4524 & 6,9 & 502 & 6,1 & 11,1 & 2973 & 12,6 & 65,7 & 1049 & 3,1 & 23,2 \\
\hline Dolj & 4073 & 6,2 & 391 & 4,7 & 9,6 & 844 & 3,6 & 20,7 & 2838 & 8,4 & 69,7 \\
\hline Gorj & 1563 & 2,4 & 57 & 0,7 & 3,6 & 907 & 3,8 & 58,0 & 599 & 1,8 & 38,3 \\
\hline Mehedinti & 2689 & 4,1 & 363 & 4,4 & 13,5 & 1388 & 5,9 & 51,6 & 938 & 2,8 & 34,9 \\
\hline
\end{tabular}

Tableau 2 - La distribution des Tsiganes en Valachie. Données élaborées à partir de la planche en annexe à la Catagrafia Țiganilor du 1840, in Analele Parlamentare ale Romaniei (1898 : 1164-1165)

Or, Marx rappelle que le Règlement organique abolissait les scutelnici, les serfs réservés au service des boyards, mais il ne dit pas qu'il maintenait l'esclavage des Tsiganes. Le Règlement s'intéresse en particulier à ceux de l'État, dont il détermine les impôts qu'ils devront verser, et il se montre particulièrement intéressé par la sédentarisation des nomades, les transformant en paysans corvéables (Achim 1994 : 90-91). Les Tsiganes étaient répartis depuis longtemps entre trois catégories de maîtres : l'État (Tsiganes de l'État, ou de la Couronne, ou du Prince : țiganii domneşti), le clergé (tiganii mănăstireşti) et les boyards (țiganii boierești). Les tableaux 2 et 4 présentent leur répartition d'après un recensement de 1839. Au cours des siècles, les princes avaient abondamment dilapidé la réserve de 
Tsiganes de l'État au moyen de fortes donations tantôt aux monastères, tantôt aux boyards ${ }^{10}$, mais les Tsiganes de l'État étaient restés nombreux, et maintenant que les boyards avaient de plus en plus besoin de main-d'œuvre pour leurs grandes propriétés, le Règlement organique leur permettait d'essayer de les transformer en fermiers corvéables, surtout les nomades, et de maintenir ceux qu'ils possédaient déjà - nomades ou sédentaires - dans un état d'esclavage.

Le mécanisme était encore plus raffiné : peut-être sous l'impulsion des premiers bougonnements abolitionnistes, y compris au niveau de l'église orthodoxe, pour satisfaire sans aucun doute des exigences socio-économiques qui avaient changé et qui voyaient la corvée plus rentable que l'esclavage, le Règlement établit que 1) des Tsiganes de l'État, surtout les nomades, peuvent être donnés aux boyards, ces derniers s'engageant à leur donner de la terre et des outils de travail en échange des corvées ; 2) ces Tsiganes/paysans paient les impôts à l'État ; 3) $1 / 10$ de ces impôts est affecté à un fonds spécial avec lequel l'État achète des Tsiganes aux boyards et les transforme en paysans corvéables, toujours employés des boyards. Ce qu'il faut souligner, c'est que ces Tsiganes/paysans ne perdent pas le statut d'esclaves de l'État, qui les transforme en paysans sédentaires liés à un seigneur, payant des impôts comme les paysans, mais bien plus élevés que ceux qu'ils payaient comme esclaves! Par exemple, en Moldavie, une annexe ad hoc du Règlement stipule que ces nouveaux fermiers doivent être demandés au ministère de l'Intérieur (art. 2) et, excepté l'exonération de la corvée la première année pour les inciter à collaborer (art. 6), pour le reste, ils auront toutes les obligations des autres paysans, avec un contrôle encore plus serré sur leur mobilité, codifié par cinq des dix-huit articles de l'annexe (art. 4, 9, $10,16,17)$, et avec une attention toute nouvelle envers leur comportement religieux (art. 13), dès lors que les législateurs estiment que la cause de leur sauvagerie (sălbătaciune) réside dans leur éloignement des « dogmes de notre sainte religion » (Regulamentele organice ale Valabiei şi Moldovei, 1944 : 257-260). En somme, avec l'argent de l'État, les boyards transforment des Tsiganes nomades en paysans sédentaires qui travaillent pour eux, y compris avec l'éventuel collant de l'instruction religieuse.

Dès la deuxième moitié du XVIII siècle, plusieurs auteurs déjà avaient divulgué en Occident la situation des Tsiganes dans les Principautés, mais Regnault se fonde essentiellement sur les travaux de deux auteurs : l'un est Auguste de Gérando ${ }^{11}$, concernant les Tsiganes de la Transylvanie, à l'époque sous le règne des Habsbourg ; l'autre est Jean-Alexandre Vaillant, dont Regnault connaît les travaux publiés jusqu'alors, mais qu'il semble également connaître personnellement car il termine la section sur les Tsiganes par cette note :

Nous ne pouvons abandonner ce sujet, sans remercier M. Vaillant, qui a bien voulu, à l'appui de ses savantes publications, nous communiquer des documents inédits, sans lesquels il nous ê̂t été difficile de nous guider dans l'bistoire obscure d'une race dédaignée (1855 : 346). 
Vaillant est aujourd'hui presque oublié dans les études romologiques, mais cette figure doit être reconsidérée. En 1829, il est appelé à enseigner dans une école prestigieuse de Bucarest, qui était en train de s'imposer comme un lieu de transmission d'idées francophiles, nationalistes et libérales. Au même moment, il sert de précepteur à des fils de boyards et de princes, y compris des princes régnants de l'époque, les Ghica. Mais il semble apporter trop de zèle à sa propagande de franc-maçon libéral et il s'immisce trop dans les histoires entre familles boyardes, toujours est-il qu'en 1834, le prince de Valachie, Alexandru II Ghica, est obligé de le démettre de ses fonctions. Il reste à Bucarest, où il publie quelques années plus tard une grammaire et un dictionnaire de roumain. Les Russes, maîtres de la politique locale de l'époque, préoccupés par le nationalisme qui se développe également par le biais de la valorisation de la langue locale, lui font obstacle de toutes les manières. Vaillant participe aux complots contre le prince avec d'autres intellectuels et jeunes boyards francisés, jusqu'à ce qu'il soit expulsé définitivement des Principautés en 1841.

De retour à Paris, Vaillant fréquente les milieux roumains en ville et devient membre de la Société Orientale, une institution, nous dit Nicolae Iorga (1919), qui pensait à un certain moment organiser des recherches sur les Tsiganes en Roumanie, recherches qui ne se réaliseront jamais. En 1844, Vaillant publie les trois volumes de la Romanie, une œuvre que Regnault cite à tout bout de champ et que Marx, indirectement, résume dans ses notes. La phrase que Marx écrit dans le manuscrit B 63, «La langue roumaine est une sorte d'italien oriental », est en fait une phrase de Vaillant. Partisan de l'unification de tous les peuples roumanophones (y compris ceux de la Transylvanie, de la Bessarabie et du banat de Timişoara), il semble que ce soit lui qui ait élargi à tous ces peuples le nom de «Roumanie » qui s'imposera par la suite, et qui était à l'époque réservé uniquement à la Valachie (Iorga 1918). Il retournera faire un court séjour en Roumanie en 1862, lorsque les deux Principautés seront enfin réunies, et il sera naturalisé roumain en 1864. Regnault évoque les épisodes roumains de Vaillant, et Marx le reprend brièvement (manuscrit B 65), mais de toute évidence, ses livres ne l'attirent pas, probablement parce que l'enseignant français partage de nombreuses caractéristiques tant avec les bohémiens conspirateurs raillés par Marx qu'avec les francs-maçons, qui ne savent que faire leurs " petits jeux » (ibidem), et surtout avec les «crétins libéraux » qui voient l'émancipation là où il y a augmentation de l'exploitation.

Regnault reconstruit les vicissitudes des Tsiganes des deux Principautés en se fondant sur les articles que Vaillant avait publiés dans l'Illustration (le célèbre hebdomadaire parisien) en 1854. Ces articles finiront dans le livre Les Rômes. Histoire vraie des vrais bohémiens, qui paraîtra en $1857^{12}$. Le livre est aujourd'hui peu digeste à cause de toutes les étymologies qui ne tiennent pas debout et que l'auteur s'obstine à proposer, et à cause de ses propositions farfelues sur les liens des Roms avec les divers peuples de la terre; mais la partie qui relate des événements autobiographiques et la situation des Roms dans les deux 
Principautés est intéressante. Cela dit, toutes les notes de Marx sur les Tsiganes, via Regnault, sont des données de Vaillant, y compris la manière dont il écrit leur nom : Rômes.

La première page du livre de Vaillant de 1857 proclame :

Vous qui, au récit d'une femme sublime par le cour et par la pensée, versez encore des pleurs de compassion sur les Nègres d'Afrique, dont l'Amérique républicaine fait ses esclaves, jetez. un regard charitable sur cette courte histoire des Rômes de l'Inde, dont l'Europe monarchique fait ses Nègres, et ces hommes, pèlerins d'Asie, ne seront plus routiers, et ces esclaves blancs seront libres.

Pour nous, nous nous estimons d'autant plus heureux d'avoir enregistré dans les Annales de l'Histoire les actes de leur affranchissement en Roumanie, que cette contrée, qui nous est chère, s'est ainsi méritée les justes sympathies de l'Europe ; et nous félicitons les princes A.-D. Ghyka, de Valaquie, et G.-A. Gbyka, de Moldavie, d'avoir entrepris et achevé cette cuvre humanitaire qui doit porter leurs noms à la postérité et les couvrir d'une gloire immortelle (1979:8).

La «femme sublime » est sans aucun doute Harriet Beecher Stow, l'auteure de La case de l'oncle Tom, un livre qui est paru en 1852, et qui eut une traduction fulgurante en roumain l'année suivante avec une préface de Kogălniceanu (1853), ce qui montre que la condition des Tsiganes était assimilée, y compris par les libéraux locaux, à celle des Noirs d'Amérique ${ }^{13}$. Mais pour le reste, plusieurs choses clochent. Bien qu'une période de fortes poussées abolitionnistes ait marqué les années précédentes, les dates officielles correspondant à la signature des décrets voïvodaux respectifs (Achim 1998 : 94-97) sur la fin de l'esclavage des Tsiganes dans les deux Principautés sont celles indiquées au Tableau 3.

\begin{tabular}{|c|c|c|}
\hline DATE & ÉMANCIPATION & PRINCE \\
\hline \multicolumn{3}{|l|}{ VALACHIE } \\
\hline 22 mars 1843 & Tsiganes de l'ítat & Gheorghe Bibescu \\
\hline 11 février 1847 & Tsiganes du clergé & Gheorghe Bibescu \\
\hline Juin 1848 & Tsiganes des boyards (non appliquece) & Gouvernement provisoire \\
\hline 20 février 1856 & Tsiganes des boyards & Barbu Stirbei \\
\hline \multicolumn{3}{|l|}{ MOLDAVIE } \\
\hline 31 janvier 1844 & Tsiganes du clergé & Mihail Sturdza \\
\hline 14 février 1844 & Tsiganes de l'Litat & Mihail Sturdza \\
\hline Loût 1848 & Tsiganes des boyards (non appliquée) & Comité révolutionnaire \\
\hline 22 décembre 1855 & Tsiganes des boyards & Grigore A. Ghica \\
\hline
\end{tabular}

Tableau 3 - Chronologie de la libération officielle des Tsiganes esclaves 
Si Grigore Alexandru Ghica a été effectivement celui qui a signé le décret d'émancipation des esclaves des boyards en Moldavie, que vient faire ici Alexandru Dimitrie Ghica ? Que vient faire l'année 1837, indiquée par Vaillant comme celle de la libération par ce prince des esclaves de l'État en Valachie information reprise par Regnault puis par Marx ? Si Gheorhe Bibescu et Barbu Ştirbei (il s'agit de deux frères, malgré leurs noms différents) sont les princes qui ont vraiment libéré les esclaves en Valachie, pourquoi les voit-on autant méprisés dans les notes de Marx, que suit Regnault, que suit Vaillant ? Dès lors que le passage où Marx évoque les Tsiganes n'est analysé ni dans l'édition roumaine ni dans l'édition italienne, pour comprendre son contenu il nous faut parler brièvement de la situation des Principautés telle que l'avait vécue Vaillant dans les années 30 du XIX ${ }^{\mathrm{e}}$ siècle, et telle qu'il la voyait en 1857.

Vaillant vit à Bucarest dans la période entre deux révolutions, celle de 1821 de Tudor Vladimirescu et celle de 1848. Il s'agit d'une période pendant laquelle les conflits sociaux historiques entre les Principautés et le gouvernement turc d'un côté, et entre les paysans et les boyards de l'autre, se rejoignent avec la tentative russe de s'élargir dans les Balkans. C'est pour cette raison que les Russes envahissent les Principautés à plusieurs reprises, entraînant des guerres avec les Turcs et parvenant à s'imposer comme " protecteurs » : à cette époque, les deux Principautés, historiquement autonomes mais vassales des Ottomans depuis le $\mathrm{XIV}$ e siècle, dépendent donc de la Porte, mais sont aussi " protégées » par les Russes. Les mouvements libéraux entrent dans ces jeux ; ils sont constitués pour la plupart de jeunes boyards formés à l'étranger ou avec des précepteurs occidentaux, qui s'appuient à leur tour sur la France et l'Angleterre. Pour les libéraux, la Russie est l'emblème du despotisme non libéral. Afin de freiner l'avancée russe, la France et l'Angleterre soutiennent la réunification des deux Principautés, mais elles soutiennent également le changement des structures féodales intérieures, dont l'abolition de l'esclavage tsigane, laquelle, à l'instar des autres formes d'esclavage, se trouvait alors dans le collimateur des mouvements abolitionnistes dans les deux pays.

À cette période, la famille Ghica (ou Ghyka, Gyka, Ghika), à laquelle appartiennent les deux princes cités par Vaillant, semble être puissante localement et très francisée culturellement : après la tentative révolutionnaire de Vladimirescu, Grigore IV Ghica est appelé sur le trône de Valachie en 1822, et il y restera jusqu'en 1828. L'oncle paternel de Grigore IV, Grigore III, prince de Moldavie, avait été décapité par les Turcs en 1777 parce qu'il n'avait pas accepté que la Bucovine (le nord de la Moldavie) passe à l'empire des Habsbourg. Depuis lors, les relations entre les Ghica et les Turcs furent mises à mal. Grigore IV déchoit avec l'invasion des Russes, mais lorsque ces derniers s'en vont, en 1834, ils mettent Alexandru II Ghica, son frère, sur le trône. Entretemps, les Russes avaient fait rédiger par une commission spéciale le Règlement 
organique dont nous avons parlé, qui d'une part établissait la victoire des boyards sur les paysans, et de l'autre tentait de réorganiser l'État dans le sens moderne (ce qui fait qu'il était haï par les boyards traditionalistes). Le secrétaire de cette commission était Barbu Ştirbei, dévoué aux Russes. Alexandru II devra appliquer le Règlement, et il se brouillera avec les Russes eux-mêmes lorsqu'il défend les intérêts de la Principauté, avec les boyards lorsque le Règlement les limoge au profit des Russes, avec les libéraux lorsqu'il doit les combattre car ils sont antipathiques à tous. Vaillant est l'un d'eux mais, ressortissant français, couvert par son consulat, il a plus de protections que les libéraux locaux. En 1844, il parle d'Alexandru II en ces termes :

Il est bon pourtant, mais sans courage; bumain, mais sans magnanimité, ami de son pays, mais plus encore de son poste ; généreux, mais par caprice; Romain, enfin, mais phanariotisé [à savoir grécisé], et malbeureusement dominé par son frère Michel, dont les conseils l'ont perdu. Ne powvant gowverner en hospodar, il prétend régir en fermier, mais A. Villara, les Pbilipesco, J. Câmpineano, J. Rosetti, G. Cantacuzène, les Bàliano et tous ceux qu'il a sacrifiés à son frère ne sont plus faits au despotisme, et il doit expier lui aussi, par le bannissement, sa pensée criminelle d'interpréter le Règlement à sa guise (1844, vol. II : 409).

Ce ne sont pas vraiment les mots auxquels nous nous attendrions, parlant d'une personne qui sera célébrée par la suite comme libérateur d'esclaves dans le texte de 1857. Le fait est qu'en 1857, Alexandru II est à nouveau sur le trône de Valachie en qualité de caimacam, c'est-à-dire de régent provisoire, à l'époque où la Principauté est un protectorat des puissances qui ont gagné la guerre de Crimée. Et Vaillant espère peut-être obtenir l'autorisation, refusée jusque là, de retourner à Bucarest.

Vaillant est expulsé en 1841, l'année même où sera chassé le frère d'Alexandru II dont il parle, Michel/Mihai, qui était alors mare ban, Premier ministre ${ }^{14}$. Alexandru II sera destitué l'année suivante, en 1842, lorsque les boyards arriveront à leurs fins et parviendront à convaincre les Russes et les Turcs de le détrôner. C'est à sa place qu'est élu Gheorghe Bibescu, qui sera renversé par la révolution de 1848 et qui trouvera refuge à Paris ${ }^{15}$. Son frère, Barbu Ştirbei, le remplacera après que les révolutionnaires aient été mis en déroute. Il restera sur le trône jusqu'en 1856, surmontant les périodes d'autres occupations étrangères pendant la guerre de Crimée.

À cette époque, les frères Bibescu furent les adversaires des Ghica (un autre frère d'Alexandru II, Constantin, subira l'offense de perdre sa femme, que Bibescu lui « volera »), qui n'étaient soutenus que par les Français; les libéraux les détestaient, alors qu'ils reprochaient aux Ghica leur manque de courage. L'ironie de l'histoire veut qu'en Valachie, ce sont précisément les frères Bibescu qui signèrent les décrets de libération des Tsiganes, et à partir de là nous pouvons imaginer la réaction de Vaillant et ses censures. Il écrit qu'en 1837 
Alexandru Ghica prend la résolution d'améliorer « le sort de cette race infortunée », et c'est cette nouvelle qui sera divulguée par Regnault et reprise par Marx dans les manuscrits. En réalité, Alexandru II, vaillant applicateur du Règlement organique, ne fait rien d'autre que d'appliquer ce qui était prescrit concernant la transformation des esclaves de l'État, surtout les nomades, en paysans corvéables, comme nous l'avons vu plus haut. Vaillant écrit :

L'État en possède quatre mille familles, qui lui rapportent quarante-cinq mille francs par an ; il [Alexandru II] les affranchit et les colonise dans les villages des Bö̈ars, à charge, par ceux-ci, de leur donner des terres de labour et de les traiter comme paysans. Cette réforme est bien accueillie, et le résultat l'a heureusement justifié. Vingt mille âmes cultivent aujourd'bui la terre qui, naguère, étaient nomades; et, loin d'y perdre, l'État a presque doublé son revenu. Le prince Alexandre Gbyka, auquel le pays est redevable de cette amélioration, peut la montrer avec orgueil à ses détracteurs. Ces Rômes colonisés sont divisés en quatre-vingt-neuf intendances, relevant d'autant d'intendants par eux élus; ils sont placés sous la surveillance immédiate du grand armash, ou directeur général des prisons; il paient annuellement 11 francs au trésor et $1 \mathrm{fr} .50$ à l'administration des prisons; les orpailleurs sont taxés à 17 francs pour le trésors et à 3 fr. pour ladite administration. Ce dixième de l'impôt, versé entre les mains du grand armash, est affecté au rachat et à la colonisation des Rômes des Bö̈ars (1979 : 359).

\begin{tabular}{|c|c|c|c|c|c|c|}
\hline $\begin{array}{c}\text { Nombre total } \\
\text { de familles }\end{array}$ & $\begin{array}{c}\text { Tsiganes de } \\
\text { lEEtat }\end{array}$ & $\%$ & $\begin{array}{c}\text { Tsiganes des } \\
\text { monastères }\end{array}$ & $\%$ & $\begin{array}{c}\text { Tsiganes des } \\
\text { boyards }\end{array}$ & $\%$ \\
\hline 65623 & 8288 & 12,63 & 23589 & 35,95 & 33746 & 51,42 \\
\hline
\end{tabular}

Tableau 4 - La division des Tsiganes en Valachie. Données élaborées à partir de la planche en annexe à la Catagrafia T,iganilor de 1840, in Analele Parlamentare ale Romaniei (1898: 1164-1165).

Or, tout ceci est défini avec précision dans le Règlement organique, qu'Alexandru II applique tout simplement. À noter qu'aucun Ghica ne figure dans la commission qui le rédigea, mais tout au plus l'un des deux Bibescu, Barbu Ştirbei ! La donnée de quatre mille familles affranchies de Tsiganes de l'État semble exagérée, dès lors que seulement deux ans plus tard, Alexandru II publie une statistique selon laquelle le nombre de familles de Tsiganes de l'État en Valachie s'élève à 8828 , comme nous le voyons dans le Tableau 4. Vaillant témoigne qu'il a vérifié personnellement l'exécution du projet, et poursuit :

Depuis la mise à exécution de ces sages mesures, j'ai eu maintes fois l'occasion de m'assurer par moi-même de leurs heureux effets. Si tous ces Rômes n'ont pas encore des cabanes comme les paysans, parce que, dans certaines localités, aux districts d'Ibraïl [Brăila] et de Ialomitza, entre autres, le bois manque ainsi que la pierre; ils sont, aussi sainement que possible, établis dans des bordeils [bordeie, maisons construites sous terre 16 ] spacieux, assez aérés pour l'été, bien clos pour l'biver, et dont on maintient la propreté par une surveillance journalière. Hommes et femmes s'occupent du labour et les 
enfants fréquentent assidûment l'école [...] Au village de J. Rosetti, près de Calarash [Calaraşi], j'ai vu, dans l'école qu'il y a fondée, des enfants rômes, de dix à douze ans, lire assez bien le roumain, faire les quatre règles de l'arithmétique, écrire passablement et indiquer sur la carte les grandes divisions géographiques [...] Enfin, quand, à l'examen solennel du collège de Bucharest, je vis le prince décerner la couronne à deux jeunes Rômes de treize à quatorze ans; quand je le vis les embrasser et quand je l'entendis les exhorter paternellement à poursuivre dans une si bonne voie, je ressentis une des plus douces satisfactions que j'aie jamais éprouvées; et [...] je bénissais leur libérateur et lui vouais une estime que, quoiqu'il en puisse penser, mes actes contre son gouvernement n'ont pas démentie [...] C'est que, en Valachie, ò̀ on vit plus avec eux que partout ailleurs, on les connaît mieux aussi, on est plus au fait de leurs gô̂ts et de leurs répugnances [...] c'est, enfin, que le prince Ghyka est heureusement doué d'un bon caur, et que, désireux de faire le bien, mais trop peu osé pour déplaire à la Russie en essayant d'améliorer le sort des paysans, il a pensé que fixer des nomades, et des esclaves faire des corvéieurs, c'était préparer un plus grand nombre de citoyens pour un prochain avenir. [...] En conséquence, le 31 janvier 1844, le prince Stourdza présente à l'Assemblée moldave un projet d'abolition de l'esclavage (1979 : 360-362).

Comme on le voit, Vaillant passa à pieds joints de 1837 à 1844 - et c'est ce que fera Marx en conséquence. Le saut de 1837 à 1844 censure la loi valaque de 1843 de Bibescu et, s'il est vrai que quelques centaines de familles de Roms se sédentarisèrent effectivement ces années-là (v. Achim 1998 : 93), il n’en reste pas moins vrai que Regnault, déjà, après avoir décrit le système des corvées, notait que « d'après ce que nous avons vu, ce n’était guère améliorer leur bien-être matériel ». Et le fait que « au moins ces affranchis entraient-ils dans la grande communauté des hommes; ils devenaient enfants du sol, Roumains au lieu de Tziganes » (1855: 383), n'est vrai qu'en partie, parce qu'en devenant paysans de facto, ils restent esclaves de jure: le Règlement organique ne prévoit pas d'affranchissements. En effet, un rapport du Trésor, approuvé par l'Assemblée parlementaire le 27 juin 1840, souligne que les familles de Tsiganes de l'État ont augmenté de 498 unités par suite des achats de boyards à l'État, alors que le 27 avril de la même année, un compte rendu mentionnait le déboursement de 86328 lei ainsi détaillé :

- 1835 : 19278 lei pour l'achat de 72 familles (267,90 lei l'une) à Madame Luxandra Suțina, femme d'un logofat (chancelier).

- 1836 : 2520 lei pour l'achat de 8 familles (315 lei l'une) à Madame Bălaşa, veuve Pleşoeanca.

- 1836 : 630 lei pour l'achat de deux familles (315 lei l'une) au vistier (trésorier) Radu Fratoştițeanu et à Ghița Pliniceanu.

- 1838 : 900 lei pour l'achat de trois familles (300 lei l'une) à Madame Teodosia Măleanca, femme d'un serdar (général).

- 1839 : 63000 lei pour l'achat de 100 familles (630 lei l'une) au serdar Nicolae Vasilescu. 
En 1842, les Tsiganes (pas les familles) sédentarisés de cette manière sont au nombre de 5668 (Filitti 1915 : 87). Ce sont les cas auxquels se réfère Vaillant, lesquels ont connu une envolée à la fin des années 1830 sous le règne d'Alexandru II, et qui représentaient une sorte de compromis entre la libération et le maintien du statu quo. Mais de là à les considérer comme une émancipation, aurait pu dire Marx, seul un « crétin libéral » pouvait le croire...

Félix Colson, un autre précepteur et secrétaire à l'ambassade française de Bucarest, libéral plus radical et peut-être moins «crétin », écrivait en 1838 :

Les cigains de la couronne qui s'élevaient en Valachie à 27.910, ont été, l'année dernière, appelés à l'état de paysans. Ils n'ont pas été établis sur les domaines de l'Etat, mais par une rouerie qui fait honte au prince Ghika, il les a donnés à des propriétaires, ses partisans politiques, ou à des familles qu'il voulait gagner. N'allezpas croire que ce soit par humanité, comme un journal d'Allemagne soudoyé l'a osé dire. Les cigains de la couronne ne paiyent au trésor que de 35 à 50 piastres. Leur industrie les fait vivre, ils se suffisent à eux-mêmes. Aujourd'bui ils doivent au gouvernement une contribution égale ou plus forte, et de plus ils paient au propriétaire des domaines sur lesquels ils sont établis les redevances multipliées d'un paysan. À ce marché je ne vois que les boyards qui ont gagné ; ils ont doublé leurs revenus (1839: 147-148).

Nous sommes à une période où le prix des esclaves avait été fixé ( $c f$. Piasere 2005), et Colson proposait l'émancipation en ces termes :

Terme moyen, les cigains se vendent de 10 à 15 ducats, c'est-à-dire de 150 à $200 \mathrm{fr}$. Il serait donc très facile à ce taux d'établir une caisse charitable. Le nombre des familles détermine la mise de fonds. Une loi peut être rendue dans les dispositions suivantes: l'esclavage est aboli. Chaque boyard recevra dix à douze ducats. Les cigains auront sept ou dix ans pour rembourser cette somme avec intérêts. Par ce moyen très simple, les cigains eux-mêmes se rachèteront, et le gouvernement y trouvera son profit ; car, admettons que pour leur faciliter ce paiement il ne les mette dans la classe des contribuables que dans dix ans, le gouvernement y gagnera encore; car maintenant ils ne paient rien. Reconnus citoyens et non paysans (ce qui reviendrait au même, à cause de l'identité des traitements), ils contribueront non seulement à la défense de l'Etat, mais encore à sa prospérité (1839: 149-150).

Comme on le voit, tout le problème tournait autour de la question de l'indemnité, et que ce soient les boyards, le prince ou les étrangers libéraux à la recherche d'un État roumain indépendant, tous faisaient leurs comptes. Ce problème retarda de plus de dix ans la libération des Tsiganes des boyards par rapport aux Tsiganes de l'État et du clergé, qui avait eu lieu dans les années 1840 Toutefois, les opinions étaient variées, et Regnault écrivait: 
En pareille matière, selon nous, l'indemnité est un contre-sens; car l'indemnité est la reconnaissance d'un droit. L'affranchissement des esclaves est une expropriation, non pour cause d'utilité publique, mais pour cause de morale publique [...] les Moldo-valaques demandent à l'Europe à être remis en possession de leurs droits. Ils ont raison sans doute. Mais pour mériter la liberté, ils doivent rendre la liberté à des hommes nés sur le même sol qu'eux, ont droit à une indemnité pour toutes les afflictions de la servitude (1855:345).

Quelques mois plus tard, les Tsiganes des boyards seront libérés plus ou moins dans les termes prévus par Colson, mais ils seront alors rachetés par l'État et non par eux-mêmes.

Les Bibescu étaient les fils d'un commerçant de chevaux de Craiova. Ils s'étaient enrichis grâce à toutes les ruses typiques de beaucoup de boyards, ils avaient amassé d'énormes richesses en peu de temps, mais par de nombreux aspects, ils affichaient le mépris typique des parvenus restés cul-terreux. Dans les descriptions des libéraux français et des jeunes boyards libéraux, ils sont présentés sous la lumière cruelle qui est reprise par Marx. Vaillant les hait, et c'est précisément dans le traitement réservé aux Tsiganes qu'il les distingue des autres boyards. Dans les années 1830, on remarque une certaine effervescence à ce propos : dès que la législation tombe sous le Règlement organique, on en voit certains, comme Ion Câmpineanu, dont le collaborateur personnel est Colson lui-même, qui libèrent leurs esclaves (en 1834), et d'autres, influencés par les doctrines de Fourier, comme c'est le cas d'Emanoil Bălăceanu, qui libèrent des esclaves (en 1836) à la condition qu'ils restent, et ces derniers vont travailler dans un phalanstère construit spécialement, mais qui fermera en l'espace de quelques années (Stan 1971: 31). En revanche, les Bibescu font tout autre chose : d'après Vaillant, ils font partie de ceux qui les envoient « aux foires comme des bestiaux », et il rapporte le cas de Barbu Ştirbei, qui, alors secrétaire de la commission ayant rédigé le Règlement organique, en bon boyard russophile qui fait carrière,

a besoin d'argent pour acheter son hôtel princier, les vend à droite et à gauche, cédant le reste au banquier Oprano pour quelques dix mille ducats. C'était alors un bien triste spectacle que celui qu'offraient les divers faubourgs de Bucharest et celui de Gorgan en particulier. On y rencontrait, ça et là, que des pauvres mères qui pleuraient leurs enfants, qu'on leur avait ravis, qui, dans leur désespoir, se frappaient la poitrine, s'arrachaient les cheveux, découvraient leur nudité et vouaient le vendeur à l'exécration des hommes et à la malédiction de Dieu (1979 : 355).

L'année suivante, l'exemple de Câmpineanu incite les libéraux à penser à une proposition de loi pour le rachat des esclaves moyennant une indemnité ; Ştirbei, exécré par l'opinion publique pour ce qu'il avait fait, pense les prendre de cours et proposer lui-même la loi ; nombreux sont ceux qui s'insurgent, il renonce bien vite à son outrecuidance et laisse la tâche à d'autres, « alors qu'il n'avait plus rien à y perdre, et ne gagna par cette velléité qu'un surcroît de ridicule » (1979 : 357). 
Le fait est que c'est son frère qui sera bientôt élu prince, après l'expulsion d'Alexandru II Ghica, et c'est lui qui promulguera la loi de libération des esclaves de l'État et du clergé. Par ailleurs, le fait est également que c'est Ştirbei lui-même, lorsqu'il deviendra à son tour prince de la Valachie, qui libèrera les esclaves des boyards. Bibescu (Bibesco 1894), aura beau jeu de démontrer dans ses mémoires que c'est lui qui a initié le processus d'émancipation. Ce qui est peut-être vrai du point de vue juridique, mais dès le départ on avait à redire sur ses présumées ouvertures libérales: Adolphe Étienne Billecocq, consul français à Bucarest de 1839 à 1846, explique bien que les esclaves du clergé qui venaient d'être libérés s'apprêtaient à mener une vie de misère encore pire qu'avant, car ils étaient privés de soutiens sociaux. Tout cela, ironisait-il, «pour donner à l'hospodar Bibesko la seule gloire qui lui manquait encore, celle d'opérer pour le bonheur de l'humanité !» (B. A. 1847: 183). L'esclavage tsigane connut également cette querelle hypocrite, à savoir à qui revenait le mérite d'avoir été le premier à émanciper les Roms...

Du point de vue de Vaillant, l'échec est atténué uniquement par le fait qu'en Moldavie, c'est en revanche un Ghica, de la branche moldave de la dynastie, qui signera la loi de libération en décembre 1855 ; il la signe effectivement quelques mois avant Ştirbei (février 1856), ce qui fait écrire à l'auteur français :

En proclamant au bruit des trompettes leur affranchissement général en Valachie, B. Shtirbéiu ne fait que céder à l'impulsion donnée en Moldavie par Grégoire Gbyka [...] Il n'est que le résultat de la double nécessité qui l'étreint et de satisfaire l'opinion et de se laver de la honte d'avoir, à vingt ans de là, vendu des hommes (1979: 460).

Le fait est que l'enseignement de Vaillant, par lequel, via Regnault, la situation des Tsiganes esclaves roumains aurait pu suggérer à Karl Marx d'importantes réflexions sur les liens de dépendance qui s'étaient formés en Europe, n'est resté en fin de compte qu'un paratexte. Avec les Principautés roumaines du début du $\mathrm{XIX}^{\mathrm{e}}$ siècle, Marx avait un cas exemplaire de ce «mélange de capitalisme et de féodalisme », de "surtravail extorqué sur le marché», et non pas avant le marché, sur lequel insistera Karl Kautsky (le fameux « renégat » de Lénine) quelques décennies plus tard, comme le souligne Moulier Boutang (1998 : 109-130). Les Tsiganes ne sont pas entrés dans la Grande Histoire des «vaincus », comme une simple citation dans Le Capital aurait pu le leur permettre. Probablement, les préjugés « occidentaux » sur les bohémiens ont bloqué l'analyste du surtravail. Dans le manuscrit B 85, Barbu Ştirbei, descendant de commerçants de chevaux devenus boyards, est appelé « effronté maquignon », mais le frère de celui-ci, Gheorghe Bibescu, est appelé dans un autre passage « bohémien enivré », seulement capable de faire des «tours de maquignon» (Marx 1964 : 51). Avec un stéréotype amplement partagé en Europe à l'époque (le Tsigane escroc qui fait le commerce de chevaux), Marx parvient ainsi à annuler de manière foudroyante l'écart entre le maître et les esclaves, l'esclavagiste et les Tsiganes : et, dans ses récits, les Roms esclaves n'entrent pas à travers ce véritable imbroglio, apte à cacher un lourd silence. 
Dans le dictionnaire de Vaillant $(1868: 124)$ le terme rob est traduit par « esclave », mais aussi par « patient, résigné », et le verbe robim par « je patiente » : les Roms esclaves ont dû faire preuve de patience, y compris avec Karl Marx!

\section{Notes}

1. Ce travail a été réalisé dans le cadre du laboratoire d'excellence LabexMed - Les sciences humaines et sociales au cœur de l'interdisciplinarité pour la Méditerranée portant la référence $10 \mathrm{LABX}-0090$. Une version élargie du présent article a fait l'objet de la communication « Karl Marx, Dora d'Istria et les Roms roumains » que j'ai lue à la Maison méditerranéenne des sciences de l'Homme d'Aix-en-Provence le 9 octobre 2013 et à l'École des hautes études en sciences sociales de Marseille le 25 octobre 2013. Je remercie encore Marc Bordigoni, Dionigi Albera, Brigitte Marin et Valeria Siniscalchi d'avoir favorisé mon séjour en Provence. La partie concernant Dora d'Istria, alias Elena Ghica, la première « féministe » qui parle de Tsiganes, figure aujourd'hui dans Piasere (2014); cf. infra note 14.

2. Sur l'évolution du concept de Lumpenproletariat chez Marx et Engels, v. Draper (1972), Huard (1988).

3. «À la cour, dans les ministères, à la tête de l'administration et de l'armée, se presse une foule de drôles, dont on peut dire du meilleur qu'on ne sait d'où il vient, toute une bohème bruyante, mal famée, pillarde, qui rampe dans ses habits galonnés avec la même dignité grotesque que les grands dignitaires de Soulouque » (Marx 1969 : 117).

4. La source de référence de Cantimori Mezzomonti est Aus dem literarischen Nachlass von Karl Marx, Friedrich Engels, und Ferdinand Lassalle, éd. F. Mehring, vol. III, p. 426 et suiv., Stuttgart, 1902. Il s'agit d'un texte d'une recension de Marx au volume Les Conspirateurs d'A. Chenu, apparu dans Politisch-ökonomische Revue en avril 1850.

5. Outre les éditeurs du livre, Stanislas Schwann, qui a découvert les manuscrits, et Andrei Oțetea, un professeur affirmé de l'Académie des sciences de Bucarest, les déchiffreurs furent P. Nyhoff, D. Schuster, G. Zane, C. Bodea (v. Oțetea 1964 : 7).

6. Je rappelle que l'on doit probablement à Bălcescu lui-même la découverte des deux plus anciens documents connus (1385 et 1387) attestant l'esclavage des Tsiganes en Valachie. Dans tous les cas, c'est lui qui communique leur existence à Paul Bataillard, le grand historien des Tsiganes, fortement roumanophile, à l'époque de son exil à Paris après l'échec du soulèvement de 1848. Bataillard diffusera la nouvelle par ces mots (1849 : 20) : «Les deux chartes qui constatent ce double fait appartiennent aux archives du monastère de Tismana ; elles sont en langue slavonne ancienne, et je n'en possède que la traduction valaque. Je dois la communication de ces deux pièces, dont j'indiquerai plus exactement la provenance en publiant l'une d'elles, à l'amitié de M. Nicolas Balcesco, jeune érudit roman qui a été membre du gouvernement provisoire de Valachie dans la récente révolution, et qui n'a cessé depuis lors, par son intelligente activité et son dévouement, d'acquérir de nouveaux titres à la reconnaissance de ses compatriotes ». Il semble que la publication prévue par Bataillard n'ait jamais eu lieu, et que la première publication soit l'œuvre de B. P. Haşdeu, plus de vingt ans plus tard, en 1875. Les textes des deux documents sont consultables aujourd'hui dans Petcuț (2009 : 62-65).

7. Nous reprenons le passage du manuscrit original en français-allemand-anglais, celui de la traduction en roumain, puis de la traduction en français.

8. C'est cette situation qui rend la traduction du terme roumain « robie » difficile. Dans un article récent en français, Florina Manuela Constantin écrit : «En conclusion, en absence d'un synonyme français, pour les termes endogènes robie, rob, on les traduira par esclavage, esclave, les termes les plus proches du point de vue de la signification » (2012: 284). 
9. Un numéro entier des Études tsiganes a été consacré à « L'esclavage des Rroms », revue Études tsiganes, $n^{\circ} 29,2007$.

10. Pour un exemple de développement de ces donations, cf. Piasere 2012: 93.

11. Il s'agit du neveu du plus connu Joseph Marie de Gérando, l'auteur de la Considération sur les diverses méthodes à suivre dans l'observation des peuples sauvages, publiée en 1800 par la Société des observateurs de l'homme.

12. En 1868, Vaillant publiera également un volume sur la langue des Roms roumains. Il est intéressant de remarquer que de nombreuses phrases rapportées dans les dialogues (p. 51-89) ont comme objet le soin du corps et de la maison, ce qui peut nous faire suspecter à juste titre que l'enseignant ou les enseignants de Vaillant étaient des vatraşi, les Tsiganes esclaves réservés aux travaux domestiques. Une phrase dit : «sam rob, ou ray », que Vaillant traduit par « Monsieur, je suis votre serviteur» (p. 55). Ackerly (1946), expert en langues roms, proposera une lecture critique mais reconnaittra la valeur de ce livre de Vaillant.

13. Je rappelle que Mihail Kogălniceanu, l'un des pères fondateurs de la Roumanie moderne, élève d'Alexander von Humboldt et de Leopold von Ranke à Berlin, publia en 1837 le premier volume consacré à la situation des Tsiganes esclaves en Moldavie et en Valachie. L'importance de ce volume est entachée du vocabulaire annexé, qui est un plagiat.

14. Dora d'Istria, la première femme qui par ce nom de plume écrivit également sur les Tsiganes en général (et sur les Roms roumains en particulier) était en réalité la princesse Elena Ghica, fille de Mihai Ghica (cf. Piasere 2014).

15. Emmanuel et Antoine, ses petit-fils, seront des amis de Marcel Proust et contribueront à construire le personnage de Saint-Loup dans la $\grave{A}$ la Recherche du temps perdu.

16. Les bordeie, autrefois maisons des paysans, sont décrites à l'époque comme des maisons typiques des Tsiganes. Il s'agissait d'habitations creusées sous terre. Dans le dictionnaire recueilli par Vaillant, «maison de terre » est traduit par ker bhuako et « terrier-hutte » par ker bhualo (1868: 112), de bhu (plus courant: $p h u$ ), «terre ». Sur les habitations enterrées, cf. P.-H. Stahl (1972).

\section{Bibliographie}

Achim V. 1998, Ţiganii în istoria României, Editura Enciclopedică, Bucureşti.

Achim V. 2004, "The Gypsies in the Romanian Principalities : The Emancipation Laws, 1831-1856”, Historical Yearbook, vol. I, p. 93-120.

Ackerley F.G. 1946, «Vaillant's 'Grammaire », Journal of the Gypsy Lore Society, $3^{\text {rd }}$ series, vol. XXV, n¹-2, p. 73.

Analele Parlamentare ale Romaniei 1898, « Pentru Catagrafia T,iganilor», Tomul IX, Partea I, Obicinuita Obştanească Adunare a Țěrei Româneşti, Legislatura II, Sesiunea III (VIII), 1839-1840, p. 1163-1166, Imprimeria Statului, Bucuresci.

Bataillard P. 1849, Nouvelles recherches sur l'apparition et la dispersion des Bobémiens en Europe, extrait de la Bibliothèque de l'École des Chartes, $3^{\mathrm{e}}$ série, vol. I, Frank, Paris.

Adolphe Billecocq, 1847, La principauté de Valachie sous le hospodar Bibesko, Wouter, Bruxelles.

Bibesco G. 1894, Règne de Bibesco, Plon, Paris.

Cantimori Mezzomonti E. 1974, «Introduzione», in K. Marx et F. Engels, Manifesto del Partito Comunista, p. 7-56, Einaudi, Torino. 
Cicanci O. 1967, «Aspecte din viața robilor de la mănăstirea Secu in veacurile XVIIXVIII », Studii si articole de istorie, vol. X, p. 155-172.

Codarcea C. 1998, «Donation religieuse et stratégie lignagère (Valachie, XVII ${ }^{\mathrm{e}}$ siècle) », Études et documents balkaniques et méditerranéens, vol. 20, p. 3-28.

Codarcea C. 2002, Société et pouvoir en Valachie (1601-1654) entre la coutume et la loi, Editura Enciclopedică, Bucarest.

Colson F. 1839, De l'état présent et de l'avenir des principautés de Moldavie et de Valachie, Chez Pougin, Paris.

Constantin F. M. 2007, « Robii țigani din Ţara Românească în justiţie: cutume şi ipostaze juridice. Studiu de caz (hrisovul din 21 Iunie 1637 », Revista istorică, vol. XVIII, n¹-2, p. 91-108.

Constantin F. M. 2009, «Robia în pravilele româneşti ale secolului al XVII-lea. Indreptarea Legii (1625)», Revista istorică, vol. XX, n¹-2, p. 73-99.

Constantin F. M. 2012, «Liens de parenté et liens sociaux chez les esclaves tsiganes de Valachie. Le sălaş au XVII e siècle », in R. Botte et A. Stella (dir.), Couleurs de l'esclavage sur les deux rives de la Méditerranée, p. 283-295, Paris, Karthala.

De Gérando A. 1845, La Transylvanie et ses habitants, Au comptoir des Imprimeurs-Unis, Paris.

Draper H. 1972, «The concept of the Lumpenproletariat in Marx and Engels », Economies et Sociétés, vol. 6, n²12, p. 285-312.

Filitti I. C. 1915, Domniile române sub Regulamentul organic 1834-1848, Edițiunea Academiei Române, Bucureşti.

Gramsci A. 1971 [1930-34], «Volontarismo e masse sociali », in Id. Il Risorgimento, p. 246-248, Editori Riuniti, Roma.

Grigoraş N. 1967, «Robia in Moldova (De la intemeierea statului pină la mijlocul secolului al XVIII-lea) (I) », Anuarul Institutului de Istorie şi Arbeologie «A.D. Xenopol», vol. IV, p. 31-49.

Grigoraş N. 1968, «Robia in Moldova (De la intemeierea statului pină la mijlocul secolului al XVIII-lea) (II) », Anuarul Institutului de Istorie şi Arheologie « A.D. Xenopol', vol. V, p. 43-85.

Huard R. 1988, "Marx et Engels devant la marginalité : la découverte du Lumpenproletariat», Romantisme, $\mathrm{n}^{\circ}$ 59. p. 5-17.

Iorga N. 1918, Histoire des relations entre la France et les Roumains, Payot, Paris.

Kogălniceanu M. 1837, Esquisse sur l'bistoire, les moeurs et la langue des Cigains, connus en France sous le nom de Bohémiens, suivie d'un recueuil de sept cents mots cigains, Behr, Berlin.

Kogălniceanu M. 1853, Prefaţă, in H.B. Stowe, Coliba lui moșu Toma, p. III-VIII, Tipografia Buciumul Român, Iaşi.

Lesnay V. 2008, «De la socialité bohémienne à la sociabilité cénaculaire (les Scènes de la vie de bohème de Henry Murger) ", in S. Moussa, Le Mythe des Bobémiens dans la littérature et les arts en Europe, p. 295-314, L'Harmattan, Paris.

Marx K. 1964 [1855-1860], Însemnări despre români (Manuscrit inédit), sous la dir. de A. Oțetea et S. Schwann, Editura Academiei Republicii Populare Române, Bucureşti.

Marx K. 1969 [1851], Le 18 Brumaire de Louis Bonaparte, Editions Sociales, Paris.

Marx K. 1971 [1855-1860], I Russi in Romania. Quattro manoscritti inediti. Introduzione, traduzione e note di L. Troisio, COO POE, Padova.

Marx K. 1974 [1867], Il Capitale. Critica dell'economia politica. Libroprimo, a cura di E. Sbardella, Newton Compton, Roma 
Mircea I. R. 1951, «Termenii rob, şerb, şi holop în documentele slave şi române », Studii si cercetari stiintifice, vol. I, $\mathrm{n}^{\circ} 2$, p. 857-873.

Moulier Boutang Y. 1998, De l'esclavage au salariat. Économie historique du salariat bridé, PUF, Paris.

Oțetea A. 1964, «Prefața », in K. Marx, Însemnări despre români (Manuscrit inédit), sous la dir. de A. Oțetea et S. Schwann, Editura Academiei Republicii Populare Române, Bucureşti, p.3-7.

Oțetea A., Zane G. 1964 «Introducere », in K. Marx, Insemnări despre români Manuscrise inedite), sous la dir. de A. Oțetea et S. Schwann, Editura Academiei Republicii Populare Române, Bucureşti, p.9-23.

Petcuț P. 2007 «L'apparition des Rroms dans les Prinipautés roumaines et les origines de l'esclavage en Moldavie et Munténie », Études tsiganes, n. 29, p. 38-47.

Petcuț P. (dir.), 2009, Rromii din România. Documente, Editura Institutului pentru Studierea Problemilor Minorităţilor Naționale, Cluj-Napoca.

Petrescu C. 2008, «Rethinking National Identity after National-Communism ? The case of Romania", Eurbistxx, version en ligne (www.eurhistxx.de).

Piasere L. 2005, «La schiavitù dei rom in Moldavia », in P. G. Solinas (dir.), La dipendenza. Antropologia delle relaz̧ioni di dominio, Argo, Lecce, p. 289-331.

Piasere L. 2011, La stirpe di Cus, CISU, Roma.

Piasere L. 2012, Roms. Une histoire européenne, Bayard, Montrouge.

Piasere L. 2014, «Dora d'Istria y los gitanos rumanos », Revista Andaluza de Antropología, n 7 , p. 23-43 (http:/ / www.revistaandaluzadeantropologia.org/).

Regnault É. 1855, Histoire politique et sociale des Principautés danubiennes, Paulin et le Chevalier, Paris.

Regulamentele organice ale Valabiei şi Moldovei, 1944, vol. I, P. Negulescu et G. Alexianu (dir.), Biblioteca Institutului de Ştințe Administrative al României, Bucureşti.

Silvestru O. 2009, «From Romantic Nationalism to National Communism. Marx, AntiRussianism and the Romanian Cause in 1855 and 1964 », Anuarul Institutului de Cercetari Socio-Umane "Gheorghe Sincai », vol. XII, p. 179-194.

Solla G. 2013, Memoria dei senzanome. Breve storia dell'infimo e dell'infame, Ombre corte, Verona.

Stahl H.-H. 1969, Anciennes communautés villageoises roumaines. Asservissement et pénétration capitaliste, CNRS, Paris.

Stahl P.-H. 1972, «L'habitation enterrée dans la région orientale du Danube », L'Homme, vol. XII, n 4 , p. 37-61.

Stan A. 1971, Le problème agraire pendant la révolution de 1848 en Valachie, Éditions de l'Académie de la République Socialiste de Roumanie, Bucarest.

Troisio L. 1971, [Introduzione], in K. Marx, I Russi in Romania. Quattro manoscritti inediti, p. V-XII, COO POE, Padova.

Vaillant J.A. 1844, La Romanie, ou histoire, langue, littérature, orographie, statistique des peuples de la langue d'or, Ardialiens, V allaques et Moldaves, résumés sous le nom de Romans, Arthus Bertrand, Paris.

Vaillant. J.-A. 1868, Grammaire, dialogues et vocabulaire de la langue des Bobémiens ou Cigains, Maisonneuve et C.ie, Paris.

Vaillant J.-A. 1979 [1857], Les Rômes. Histoire vraie des vrais bobémiens, Les Textes Essentiells, Paris. 